\title{
CONSIDERAÇÕES ESTATÍSTICAS RELATIVAS A SEIS SÉRIES MENSAIS DE TEMPERATURA DO AR DA SECRETARIA DE AGRICULTURA E ABASTECIMENTO DO ESTADO DE SÃO PAULO
}

\author{
GABRIEL CONSTANTINO BLAIN \\ Instituto Agronômico de Campinas (IAC), Campinas, SP \\ gabriel@iac.sp.gov.br
}

Recebido Março 2009 - Aceito Julho 2010

\begin{abstract}
RESUMO
O objetivo do trabalho foi detectar tendências e variações climáticas nas séries mensais de temperatura máxima (Tmax) e mínima (Tmin) do Estado de São Paulo. A fim de obter melhor adequação, entre a probabilidade de ocorrência dos erros estatísticos tipo I e II, foram utilizados métodos paramétricos (teste t, $\mathrm{F}$ e razão da verossimilhança) e não paramétricos (teste sazonal de Mann-Kendall e de Pettitt). As séries de Tmin das localidades de Campinas, Cordeirópolis, Ribeirão Preto e, especialmente Ubatuba, apresentam fortes indícios de tendências e variações climáticas nos últimos 60 anos. Nas séries de Monte Alegre do Sul e Pindorama tais indícios são observados de forma pouco significativa. As alterações de ordem climática observadas nas séries de Tmax são bastante inferiores às observadas nas séries de Tmin. Dentre todas as localidades analisadas, a de Ubatuba foi a que apresentou as tendências de elevação mais significativas nos dados de temperatura do ar. Os resultados também indicaram que no mês de Abril podem ser verificados, em todas as seis localidades, os indícios mais significativos de elevação nos valores mensais da Tmax e, em especial, da Tmin. Em contra partida, o mês de Setembro mostrou-se o menos sujeito a elevação nos valores dessas duas variáveis meteorológicas.
\end{abstract}

Palavras Chave: tendências climáticas, variações climáticas, mudanças climáticas

\begin{abstract}
STATISTICAL CONSIDERATIONS OF SIX MONTHLY AIR TEMPERATURE SERIES OF THE STATE OF SÃO PAULO, BRAZIL

The aim of the work was to detect trends and climate variations in monthly maximum (Tmax) and minimum (Tmin) air temperature series of the State of São Paulo. In order to obtain a better balance between the probabilities associated with type I and II errors, parametric methods (tests t, F and the likelihood ratio test) and non-parametric methods (Seasonal Mann-Kendall test and Pettitt test) were used. In the series of Campinas-SP, Cordeirópolis-SP, Ribeirão Preto-SP and, especially Ubatuba-SP, strong evidences of climate trends and climate variations in the last 60 years were detected. In the Monte Alegre do Sul-SP and Pindorama-SP series such climate alterations were not observed. It was also observed that the significance level of climate changes in the Tmax series are lower than those observed in the Tmin series. In the Ubatuba-SP series the highest climate alteration level, among all analyzed Tmax and Tmin series was detected. It was observed that the April months were the most affected by climate changes. On the other hand, the September months were little affected by climate change, in all analyzed Tmax and Tmin series.
\end{abstract}

Keywords: climate trends, climate variation, climate change

\section{INTRODUÇÃO}

Nas últimas décadas, foram observados diversos avanços da agrometeorologia na redução da vulnerabilidade agrícola frente às adversidades meteorológicas. Entre esses, ressalta-se o zoneamento agrometeorológico. Frequentemente, na elaboração desse método agrícola, inferências estatísticas são realizadas com base em um período amostral (1961 a 1990, por 
exemplo), e posteriormente extrapoladas para anos futuros. Em outras palavras, espera-se que a probabilidade de ocorrência associada a um dado valor de temperatura do ar ou precipitação pluvial, estimada com base no período analisado, mantenha-se razoavelmente constante em demais épocas futuras, tornando evidente a importância de investigações relativas a variações amostrais em séries meteorológicas. Aliado a esse fato, diversos trabalhos científicos apontam indícios de alterações nos padrões climáticos globais. Karl et al. (1999), utilizando dados de diversas partes do globo, indicam tendência global de elevação no número de dias "excessivamente quentes" (extremely hot days) observados em cada ano. Alexander et al. (2006) analisando dados globais extremos de temperatura do ar e precipitação pluvial, na escala diária, identificaram, em 70\% das regiões analisadas, significativa elevação nas temperaturas noturnas. Vincent et al. (2005) observaram tendências de elevação ligadas principalmente à temperatura noturna. Segundo esses autores, as estações em que foram detectadas tendências significativas concentram-se, especialmente, nas costas leste e oeste da América do Sul. Com base em dados mensais de temperatura atmosférica (1913 a 1995) oriundos de 17 estações meteorológicas localizadas na Amazônia brasileira, Victória et al. (1998) observaram tendências de elevação da ordem de $0,56^{\circ} \mathrm{C} /$ século. Segundo esses autores, essa elevação teve início entre o fim da década de 1960 e começo da de 1970.

Contudo, é oportuno ressaltar que estudos sobre alterações nos padrões climáticos globais não são recentes. A nota técnica $n^{\circ} 79$ (OMM, 1966) preocupa-se exclusivamente com esse fenômeno, afirmando que a análise de séries temporais meteorológicas demonstra claramente a inconstância do clima. Para esse relatório, mudança climática é um termo genérico que engloba todas as formas de inconstância nos padrões climáticos, como tendências, caracterizadas por uma elevação ou diminuição suave e monótona nos valores médios de uma série meteorológica, e variações climáticas, conceituadas como flutuação ou componente desta em escala de tempo, suficientemente longa capaz de resultar em inconstância nos parâmetros estatísticos de períodos sucessivos de pelo menos 30 anos da variável meteorológica em questão.

Sob o ponto de vista agrometeorológico, a principal preocupação com possíveis alterações no clima parece estar relacionada ao aumento do risco climático associado ao setor agrícola. De acordo com Zullo et al. (2006), as pesquisas agrícolas devem considerar, entre outros fatores, impactos relacionados à mudanças no clima terrestre. Para Pinto et al. (2008), os cenários de clima futuro com temperaturas mais elevadas poderão acarretar em severa redução da área cultivada de café no Estado de São Paulo. Dessa forma, o objetivo do trabalho é detectar tendências e variações climáticas nas séries mensais de temperatura do ar máxima (Tmax) e mínima (Tmin) do Estado de São Paulo, determinando o grau de significância estatística e a data (aproximada) de início das mesmas.

\section{MATERIAL E MÉTODOS}

Foram utilizados dados mensais de temperatura do ar máxima e mínima pertencentes ao Instituto Agronômico (IAC/APTA) da Secretaria de Agricultura e Abastecimento do Estado de São Paulo. Na Figura 1 são ilustradas as coordenadas geográficas dos postos utilizados. A exceção das localidades de Ubatuba (1956 a 2007) e Pindorama (1951 a 2007) todas as demais localidades foram escolhidas de forma a gerar duas amostras ou sub-períodos de 30 anos de dados (1948 a 2007).

Os testes utilizados foram: teste t-student, teste $\mathrm{F}$, teste da razão da verossimilhança $\left(\Lambda^{*}\right)$, teste Sazonal de MannKendall (SMK) e teste de Pettitt. Os três primeiros métodos são conceitualmente denominados de paramétricos, por assumirem que a amostra pode ser ajustada a uma distribuição teórica/ paramétrica. Os outros dois não fazem distinção quanto à distribuição da qual os dados são oriundos, sendo, com isso, considerados não-paramétricos.

Em Von Storch e Zwiers (1999) e Wilks (2006), podem ser encontradas descrições detalhadas das propriedades e limitações dos testes t e F. O $\Lambda^{*}$ é indicado por Schickedanz e Krause (1969) e Wilks (2006) como sendo uma interessante alternativa, para verificar se distintos períodos de uma série histórica podem ser considerados oriundos da mesma população. O $\Lambda^{*}$ compara a verossimilhança associada a uma hipótese de nulidade (Ho) à verossimilhança associada a uma hipótese alternativa $\mathrm{H}_{\mathrm{A}}$. Para a condução deste método os parâmetros da distribuição ajustados a toda série disponível $\left(\mathrm{k}_{0}\right)$ e os ajustados para cada amostra ou sub-período em que série foi sub-dividida $\left(\mathrm{k}_{\mathrm{A}}\right)$ devem ser estimados pelo método da máxima verossimilhança. $\mathrm{Sob}_{0}$, a distribuição dos valores de $\Lambda$ * é qui-

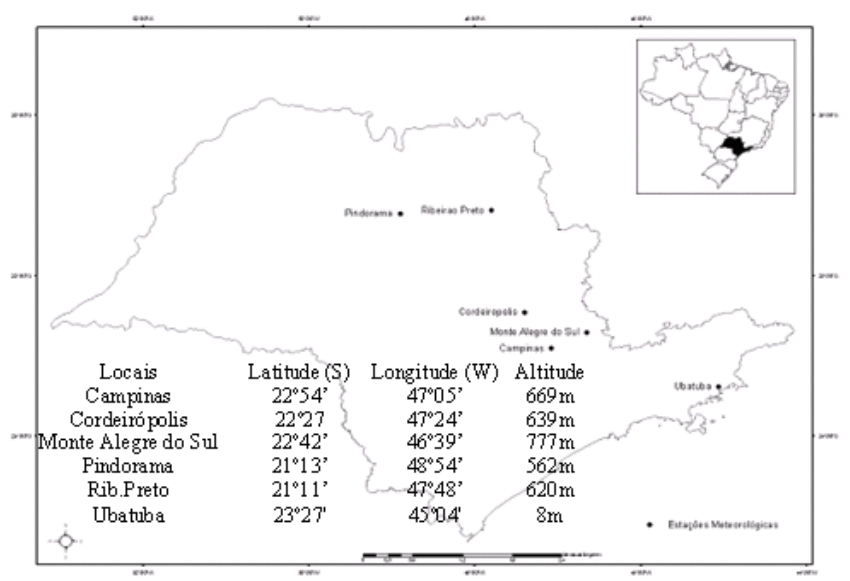

Figura 1 - Postos meteorológicos pertencentes à Secretaria e Agricultura e Abastecimento do Estado de São Paulo. 
quadrado com graus de liberdade $\mathrm{GL}=\mathrm{k}_{\mathrm{A}}-\mathrm{k}_{0}$. Considerando o nível 10\% de significância, o valor crítico desse teste é 4,61. O teste é definido da seguinte forma:

$$
\Lambda^{*}=2 \operatorname{Ln}\left[\Lambda\left(\mathrm{H}_{\mathrm{A}}\right) / \Lambda(\mathrm{Ho})\right]=2\left[\mathrm{~L}\left(\mathrm{H}_{\mathrm{A}}\right)-\mathrm{L}(\mathrm{Ho})\right]
$$

Considerando as duas amosras relativas aos anos de 1948/1977 e 1978/2007 compostas por $x_{i}$ valores, o teste $\Lambda^{*}$, quando é utilizada a distribuição normal (DN), é calculado por:

$$
\begin{aligned}
\Lambda^{*}= & 2\left\{\left[\sum_{i=1948}^{2007} L_{1}\left(\mu_{1}, \sigma_{1} ; x_{i}\right)+\sum_{i=1948}^{1977} L_{1}\left(\mu_{2}, \sigma_{2} ; x_{i}\right)\right]-\right. \\
& {\left[\sum_{i=1948}^{200} L_{1}\left(\mu, \sigma ; x_{i}\right)\right\} }
\end{aligned}
$$

Onde $\sigma$ e $\mu$ são, respectivamente, o desvio padrão e a média aritmética dos dados no período;

$$
\begin{gathered}
\mathrm{L}\left(\mu, \sigma ; \mathrm{x}_{\mathrm{i}}\right)=-\ln (\sigma)-\ln \left[(2 \pi)^{1 / 2}\right]- \\
(1 / \sigma)\left\{\sum\left[\left(\mathrm{x}_{\mathrm{i}}-\mu\right)^{2}\right]\right\}
\end{gathered}
$$

Comparando-se esses três métodos paramétricos, nota-se que os testes t e F analisam, respectivamente, apenas as medidas de posição estatística média e variância amostral. $\mathrm{O} \Lambda^{*}$, em contra partida, investiga a probabilidade teórica de ocorrência associada a cada valor oriundo de cada período.

O ajuste de cada sub-período, bem como, de cada série mensal à distribuição normal $(\mathrm{DN})$ foi verificado por meio do teste de aderência Kolmogorov-Smirnov/Lilliefors (KS) conforme descrito em Crutcher (1975) e Wilks (2006).

Inicialmente proposto por Mann (1945) e Kendall e Stuart (1967), o teste não paramétrico de Mann-Kendall (MK), quando comparado a outros métodos paramétricos, é bastante robusto quanto a desvios da normalidade e não-estacionaridade dos dados, justificando o fato do mesmo ser muito utilizado em estudos de tendências em séries temporais. Contudo, é necessário ressaltar que a presença de significativas correlações seriais, afeta a sensibilidade desse teste (Hamed e Rao, 1998 e Bayazit e Onoz, 2007). Nesse sentido, a presença de auto-correlação positiva aumenta a probabilidade de detecção de falsas tendências de elevação (adotando-se como Ho a inexistência de tendências, a presença de auto-correlação positiva aumento a probabilidade do erro tipo I). Características opostas são observadas na presença de auto-correlações negativas. A fim de adaptar o MK para séries auto-correlacionadas, bem como, lidar com dificuldades impostas por possíveis sazonalidades, Hirsch et al. (1982) e Hirsch e Slack (1984) propuseram o método denominado de Mann-Kendall Sazonal. No caso de séries mensais, o SMK deve ser calculado organizando os dados em forma de matriz; em que as colunas são preenchidas com os valores da série relativos a cada mês do ano. Por exemplo, para o caso de 50 anos de dados mensais, tem-se uma matriz (50x12; com os valores dentro de cada coluna classificados de acordo com o ano em ordem crescente). $\mathrm{O}$ fator $\mathrm{T}$ do método original é inicialmente estimado para cada coluna ( $\mathrm{Tj}$; mês):

$$
S=\sum_{j=1}^{12} T_{j} \text { para } \mathrm{T}_{\mathrm{j}}=\sum_{\mathrm{k}<1} \operatorname{sinal}\left(\mathrm{Z}_{\mathrm{lj}}-\mathrm{Z}_{\mathrm{kj}}\right) \text {, no caso, } \mathrm{j}=1 \ldots 12
$$

$$
\operatorname{Var}(S)=\sum_{j=1}^{12} \operatorname{Var}\left(T_{j}\right)+\sum_{\substack{j, g=1 \\ g \neq j}}^{12} \operatorname{Cov}(T j: T g), \operatorname{para} \mathrm{j} \neq \mathrm{g}
$$

$$
\operatorname{Var}\left(T_{j}\right)=\frac{n_{j}\left(n_{j}-1\right)\left(2 n_{j}+5\right)-\sum_{i=1}^{m} t_{i}\left(t_{i}-1\right)\left(2 t_{i}+5\right)}{18}
$$

Em que $n_{j}$ é o número de valores de cada série $j$ mensal, $\mathrm{m}$ é o número de grupos de valores adjacentes iguais e $t_{i}$ é o número de valores presentes em cada um desses grupos. Cov ( $T j: T g$ ) é a covariância entre duas estatísticas $T j T g$. O valor final do SMK é dado por:

$$
\mathrm{SMK}=\left\{\begin{array}{l}
\frac{\mathrm{S}-1}{\sqrt{\operatorname{Var}(\mathrm{S})}} ; \text { para } \mathrm{S}>0 \\
0 ; \text { para } \mathrm{S}=0 \\
\frac{\mathrm{S}+1}{\sqrt{\operatorname{Var}(\mathrm{S})}} ; \text { para } \mathrm{S}<0
\end{array}\right\}
$$

Autores como Marengo et al. (2007) utilizam o nível de significância $\mathrm{p}=0,05$ para a condução desse método. Adotando esse mesmo nível, Ho não será rejeitada sempre que -1,96< SMK $<1,96$. Tendências de elevação ou queda resultam em valores positivos ou negativos do SMK. Segundo Lettenmaier et al. (1994) a vantagem da aplicação do SMK é relacionada ao fato de que alterações em estações em que são esperados baixos valores das variáveis sob investigação não são influenciadas por elevados valores de outras épocas.

O teste não paramétrico de Pettitt (Pettitt, 1979) indica se duas amostras (no presente caso, oriundas da mesma série) $\mathrm{Y}_{1}, \ldots, \mathrm{Y}_{\mathrm{t}}$ e $\mathrm{Y}_{\mathrm{t}+1}, \ldots, \mathrm{Y}_{\mathrm{T}}$ são da mesma população. A estatística $\mathrm{U}_{\mathrm{t}, \mathrm{T}}$ verifica o número de vezes que um elemento da primeira amostra é maior do que um elemento da segunda. A estatística $\mathrm{U}_{\mathrm{t}, \mathrm{T}}$ é estimada pela Equação 8.

$$
U_{t, T}=U_{t-1, T} \sum_{j=1}^{T} \operatorname{sinal}(y t-y j) \quad \text { para } \mathrm{t}=2 \ldots . \mathrm{T} \text { e } 1 \leq \mathrm{t} \leq \mathrm{T}
$$


Após essa etapa, a estatística $\mathrm{k}(\mathrm{t})$ assume o maior valor absoluto dos fatores Ut,T; indicando o ponto aproximado da alteração nos valores da série (changing point). A significância de $\mathrm{k}(\mathrm{t})$ é dada pela Equação 9, em que o valor crítico desse fator é estimado.

$$
k(t)_{\text {critico }}=\sqrt{\frac{\left(T^{3}+T^{2}\right)[-\ln (p / 2)]}{6}}
$$

Analisando-se as Equações 8 e 9, e conforme Back (2001) verifica-se que este teste é uma versão do teste de populações de Mann-Whitney (teste U). Victoria et al. (1998), Back (2001) e Mortatti et al. (2004) adotam o nível de significância de $\mathrm{p}=5 \%$ para a condução desse método.

\section{RESULTADOS E DISCUSSÃO}

A justificativa em adotar investigações paramétricas e não paramétricas é baseada nas afirmações de Dale (1968) e Sansigolo e Nery (2000), relativas ao maior embasamento estatístico da descrição climática quando são utilizados modelos teóricos. Dessa forma, pode-se inferir que o primeiro passo no estudo de alterações climáticas, seria o ajuste das séries meteorológicas a uma distribuição teórica. A análise dessas possíveis mudanças seria realizada por meio do estudo dos parâmetros das distribuições relativas a cada amostra dessa série, diminuindo, com isso, a probabilidade de que as diferenças entre cada subperíodo seja atribuída a deficiências no tamanho da amostra (falha na descrição climática da região). Em contra partida, segundo Frei e Schar (2000), análises de tendências em longas séries meteorológicas confrontam-se com a dificuldade fundamental de que as variações estocásticas limitam a confiabilidade com que possíveis tendências podem ser detectadas. Esses autores especificam os dois tipos de erro que podem ocorrer: a) indicação de tendências climáticas, quando há apenas flutuações essencialmente controladas pelas variações estocásticas (erro tipo I); b) uma real tendência climática não é identificada por estar "encoberta" por flutuações estocásticas de pequenas escalas temporais (erro tipo II). Esses erros estão presentes em todo e qualquer tipo de análise de mudanças climáticas (Frei e Schar, 2000). No presente caso, apesar da suavização causada pelo ajuste das distribuições empíricas à $\mathrm{DN}$ diminuir, a probabilidade do erro tipo I aumenta, obviamente, a do tipo II. Com isso, torna-se também interessante analisar possíveis alterações climáticas considerando testes não paramétricos.

Observando a Equação 7, nota-se que a introdução da matriz covariância reduz, para o caso de persistência positiva, o valor final da estatística SMK, diminuindo a probabilidade do erro tipo I. Em contra partida, verifica-se que o somatório da Equação 5 considera apenas a covariância (ou a dependência temporal) entre 11 meses adjacentes. Em outras palavras, o SMK assume que após o deslocamento "lag 11", a auto-covariância da série de dados mensais tornam-se não significativas. Em termos de estatística climatológica, essa característica do SMK exige que a probabilidade de ocorrência de um dado valor $X_{t}$ seja influenciada de forma não significativa por um valor temporalmente anterior $\mathrm{Xg}$ (para $\mathrm{g}>11$ ). Observando os demais métodos empregados, paramétricos e não paramétricos, verifica-se que cada amostra mensal é analisada separadamente (12 conjuntos mensais). Com isso, ainda que de maneira informal, a convenção de inexistência de auto-correlação significativa após 11 meses (lags) também é assumida por todos os demais métodos empregados. Todos os sub-períodos e séries analisadas podem, de acordo com o KS, serem ajustadas, até $10 \%$ de significância, à DN.

Analisando-se as Equações 1 a 3, observa-se que o $\Lambda^{*}$ é bastante adequado para verificar variações nos parâmetros das funções densidade de probabilidade (FDPN) associada a diferentes sub-períodos de uma mesma série. Contudo, o sequenciamento temporal dos valores constituintes de cada amostra não é analisado. Nesse aspecto, nota-se, por meio das Equações 4 a 12, que essa disposição temporal tem profunda influência no valor final do SMK. Por meio dessas últimas expressões, verifica-se que esse método não paramétrico, é adequado para a detecção de tendências monótonas em uma série temporal. Sob o ponto de vista meteorológico, essa diferença entre o $\Lambda^{*}$ e o SMK pode ser interpretada considerando as definições de variações e tendências climáticas da nota OMM (1966). Inferi-se que o $\Lambda^{*}$ é mais adequado para análise de variações, ao passo que o SMK é voltado à detecção de tendências climáticas.

As diferentes formas gráficas das FDPN observadas entre os sub-períodos de 1948-1977 e 1978-2007 (Figuras 2 a 7) ilustram, no caso do zoneamento agrícola, a fragilidade da adoção da premissa de que as propriedades ou parâmetros estatísticos das séries de dados de Tmin sejam independentes da escolha de uma origem temporal $t$ (definição informal de estacionaridade).

Campinas: Em todos os meses são observadas significativas elevações monótonas dos valores de Tmin, conforme indicado pelo SMK. Nesse aspecto, ressalta-se que apesar de serem verificados valores significativos de $\Lambda^{*}$ e do teste $\mathrm{t}$, em praticamente todos os agrupamentos mensais, há de acordo com o teste $\mathrm{F}$, homocedasticidade das variâncias amostrais em 11 meses (exceção de Janeiro). Nos meses de Setembro o teste $\Lambda^{*}$ não indicou diferenças significativas entre as amostras.

Cordeirópolis: Assim como observado para Campinas, apenas nos agrupamentos relativos ao mês de Janeiro, não 
foi observada homocedasticidade das variâncias amostrais. Verifica-se, também, valores significativos do SMK em todos os períodos analisados, sendo que as menores magnitudes desse teste não paramétrico ocorreram entre Maio e Setembro. Nos meses de Agosto e, especialmente, Setembro, não há valores significativos de nenhum dos métodos paramétricos utilizados no estudo.
Monte Alegre do Sul e Pindorama: Essas duas localidades apresentam as menores taxas de elevação dos valores de Tmin, quando comparadas às demais séries utilizadas, considerando-se tanto os métodos paramétricos como os não paramétricos. Em Monte Alegre do Sul o SMK é significativo apenas nos meses de Abril e Dezembro. Em Pindorama esse
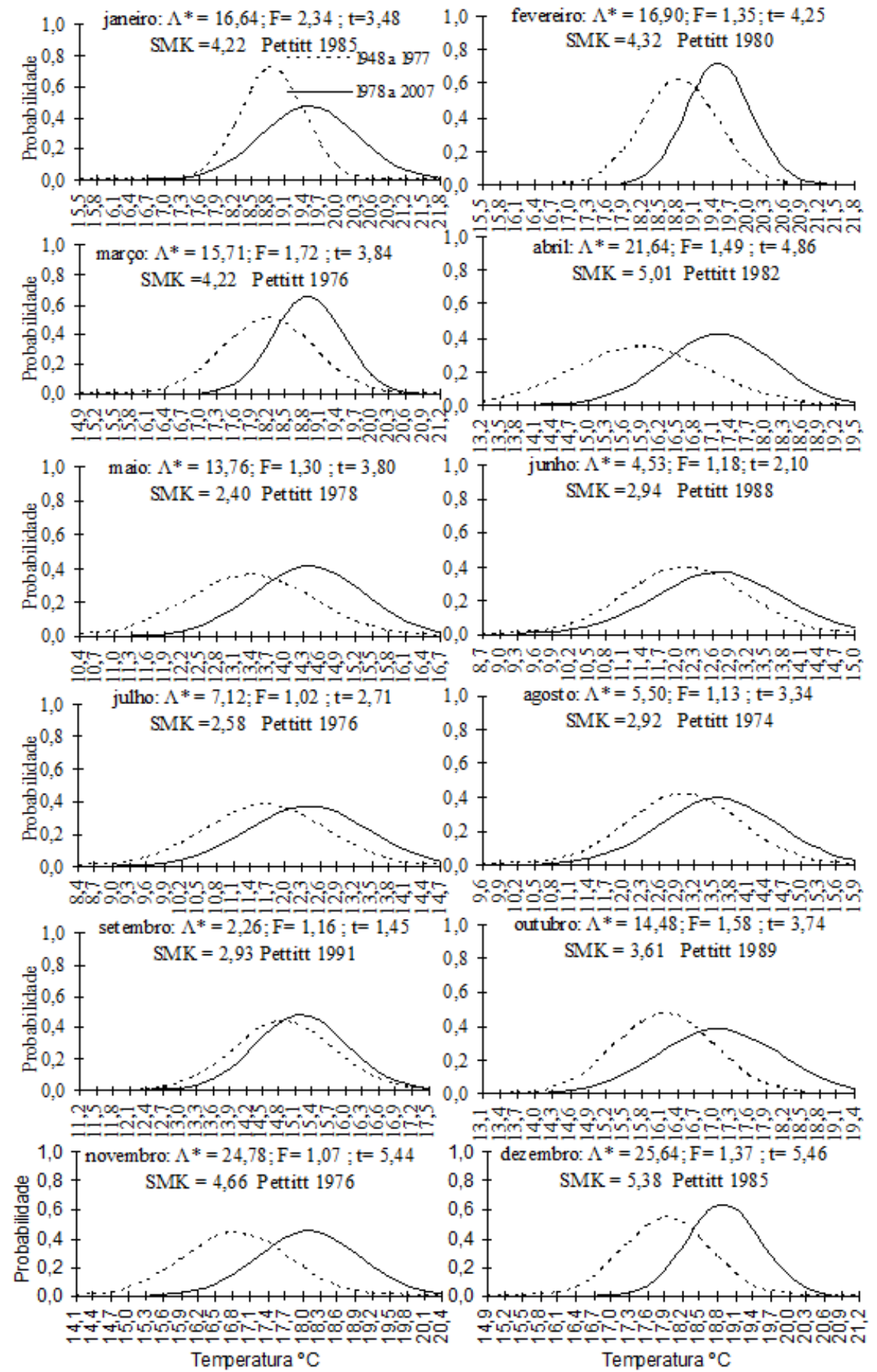

Figura 2 - Aplicação dos testes razão da verossimilhança $\left(\Lambda^{*}\right)$, F, t, Mann-Kendall Sazonal (SMK) e Pettitt para a localidade de Campinas-SP. Temperatura mínima do ar. Os respectivos valores críticos são 4,61; 1,86; 2,01; [-1,96 a +1,96] e 367,00. 
teste é significativo em Março, Abril e Dezembro. À exceção do agrupamento de Maio em Monte Alegre do Sul e de Dezembro em Pindorama há homocedasticidade da variância em todas as amostras analisadas. Assim como nas localidades de Campinas e Cordeirópolis, as menores taxas de elevação de Tmin estão contidas no período entre Maio e Setembro. Nas duas localidades chega-se a verificar deslocamentos não significativos à esquerda das FDPN associadas às amostras de Agosto e, especialmente, Setembro, relativas aos anos de 1978 a 2007.

Ribeirão Preto: Valores significativos do SMK em todos os meses. Não há homocedasticidade da variância em cinco agrupamentos mensais: Janeiro, Fevereiro, Março, Outubro e Dezembro. Nos meses de Setembro o teste $\Lambda$ * não indicou, mais uma vez, diferenças significativas entre as amostras.

Ubatuba: Nessa localidade são observadas as maiores taxas de elevação dos valores de Tmin ocorridas entre todas as séries analisadas. Essa característica pode ser verificada por meio dos testes paramétricos e não paramétricos. É interessante ressaltar que os valores do $\Lambda^{*}$ e do SMK são, de forma geral, superiores aos observados em regiões com graus de urbanização mais acentuados (Ribeirão Preto e, especialmente, Campinas). Verifica-se que apesar do marcante deslocamento à direita
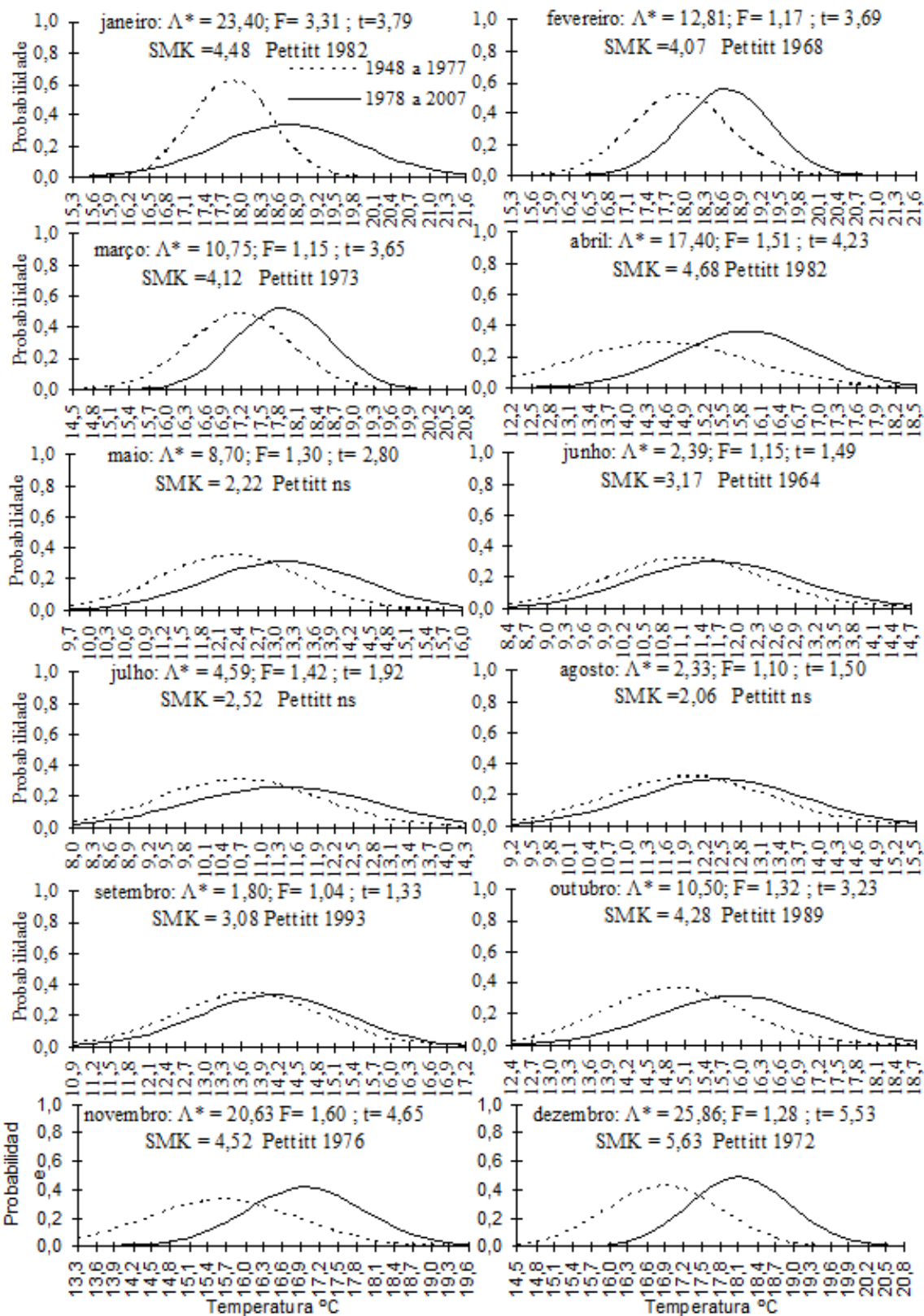

Figura 3 - Aplicação dos testes razão da verossimilhança $\left(\Lambda^{*}\right)$, F, t, Mann-Kendall Sazonal (SMK) e Pettitt para a localidade de Cordeirópolis-SP. Temperatura mínima do ar. Os respectivos valores críticos são 4,61; 1,86; 2,01; [-1,96 a +1,96] e 367,00. 
das distribuições associadas às amostras relativas aos anos mais recentes, apenas nos meses de Abril e Dezembro foram observados testes F significativos, a 5\% de significância. Nesses meses, verifica-se queda nos valores das variâncias entre os dois sub-períodos analisados. Ressalta-se que nos meses de Setembro, são observados os menores valores de $\Lambda^{*}$. Segundo o teste de Pettitt, o ponto inicial das alterações citadas ocorreu, predominantemente na década de 1970, excluindo-se os meses de Setembro (1987) e Outubro (1985).

Sob o ponto de vista espacial, as diferentes taxas de elevação dos valores de Tmin, especialmente nas séries de Monte Alegre do Sul e Pindorama (alterações pouco significativas), parece não corroborar a hipótese de que forçantes radioativas de escala global sejam as únicas responsáveis pelas elevações dos dados relativos às localidades de Campinas, Cordeirópolis e Ribeirão Preto. Nesse sentido, devido à proximidade geográfica entre essas estações, essa incoerência espacial, constitui-se em uma indicação da presença de importantes forçantes locais nas taxas de elevação de Tmin presentes nessas três séries. Essa hipótese deve ser investigada, por futuros estudos físicos/

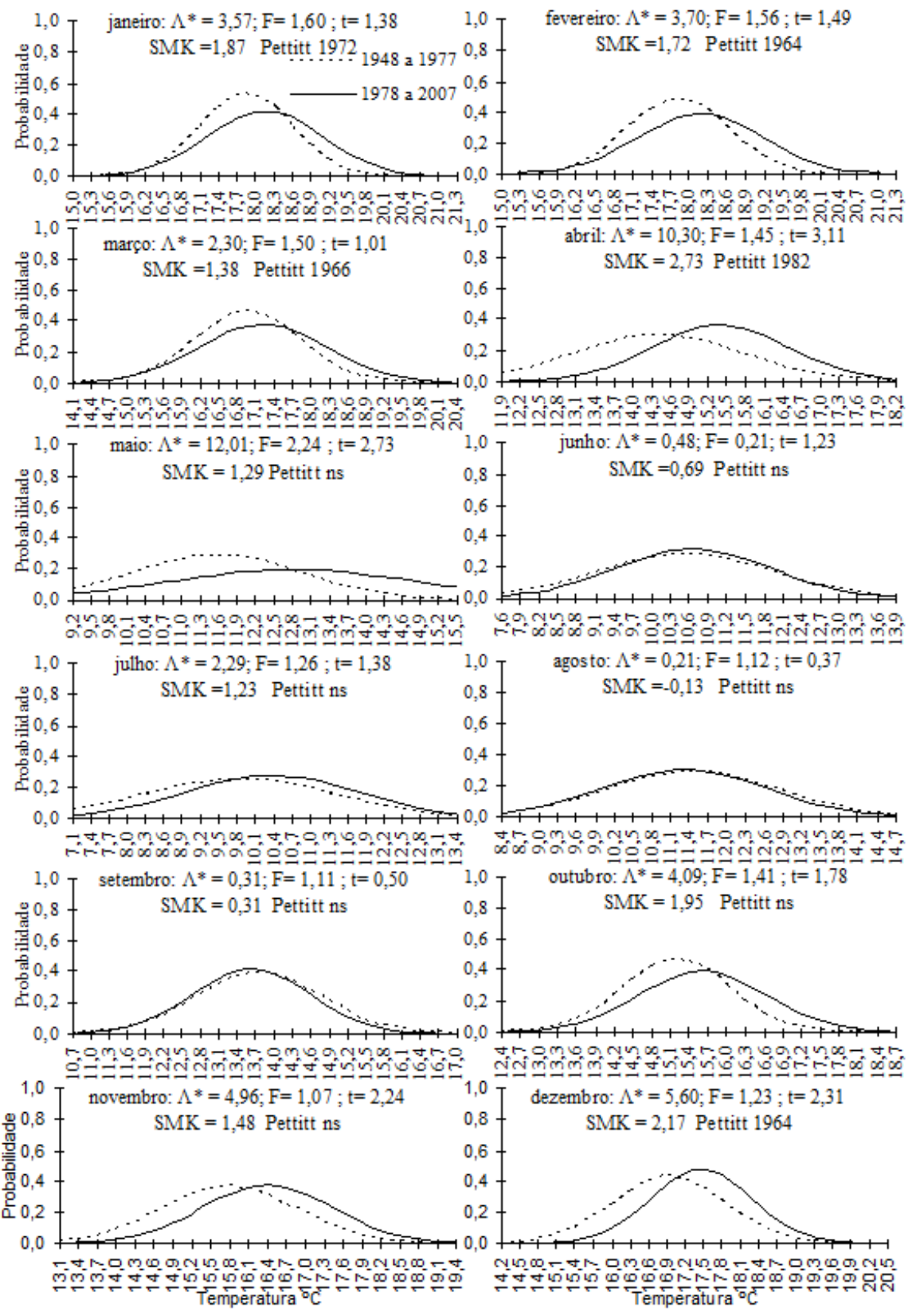

Figura 4 - Aplicação dos testes razão da verossimilhança ( $\left.\Lambda^{*}\right)$, F, t, Mann-Kendall Sazonal (SMK) e Pettitt para a localidade de Monte Alegre do Sul-SP. Temperatura mínima do ar. Os respectivos valores críticos são 4,61; 1,86; 2,01; [-1,96 a +1,96] e 367,00. 
meteorológicos, tendo em vista a constante utilização dessas séries da Secretaria de Agricultura e Abastecimento em políticas rurais. Ressalta-se também, que especialmente os resultados da localidade de Ubatuba corroboram as indicações de Vincent et al. (2005) descritas no item 1.

Sob o ponto de vista temporal, verifica-se, de forma geral, que as menores taxas de elevação ocorreram entre os meses de Maio e Setembro, sendo que nesse último mês essa característica é marcante em todas as localidades. Para os postos meteorológicos de Campinas, Cordeirópolis, Monte Alegre do Sul, Pindorama, Piracicaba e Ribeirão Preto, o teste de Pettitt não indicou marcantes concomitâncias nas datas iniciais das alterações verificadas, tanto quando são considerados os diferentes agrupamentos mensais dentro de uma mesma série, como quando são consideradas as distintas localidades para um mesmo mês. Contudo, é necessário observar que o único mês (Abril) em que foram detectados valores significativos em todos os métodos empregados (excluindo-se o teste F) apresenta, para as séries
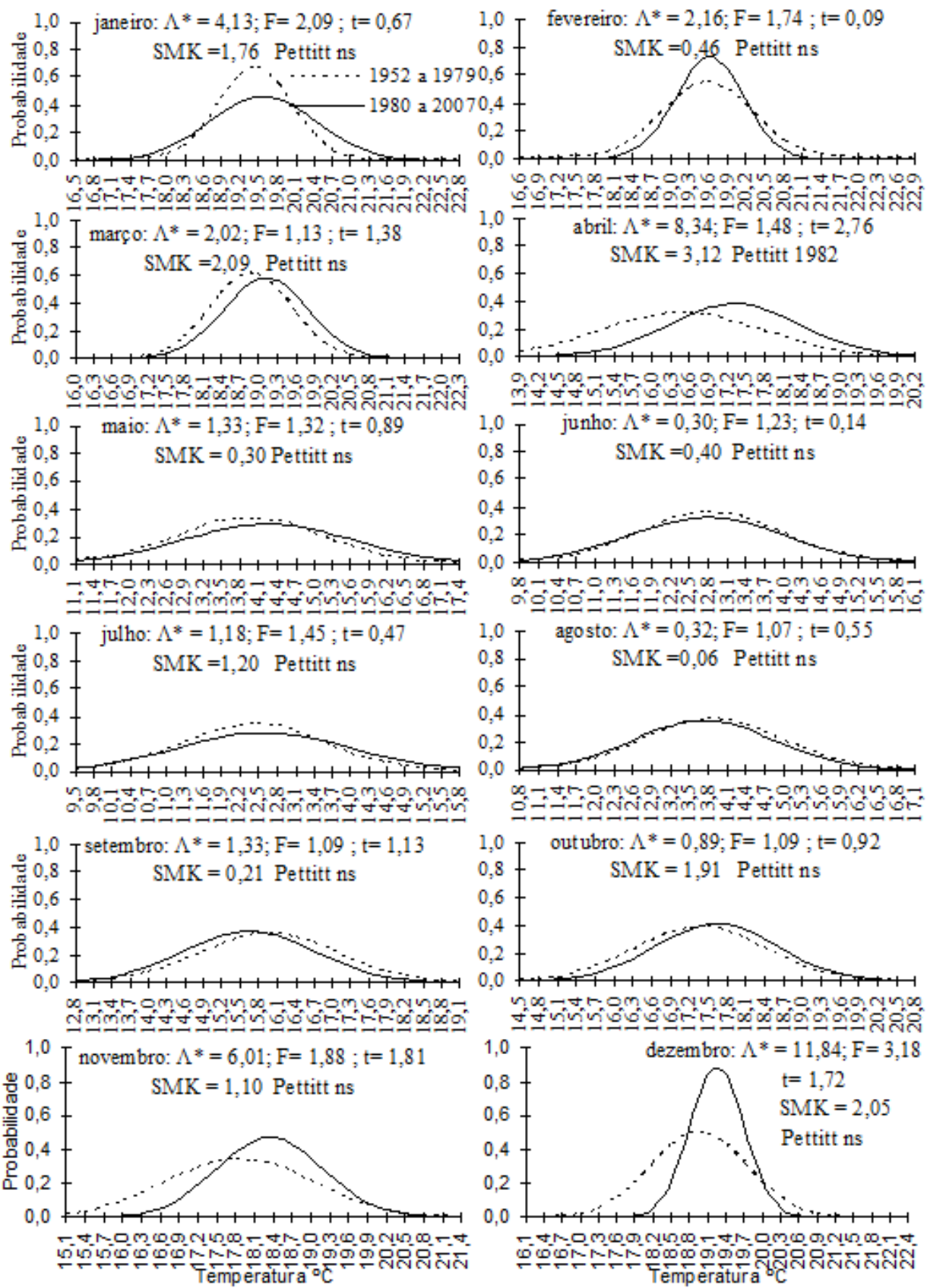

Figura 5 - Aplicação dos testes razão da verossimilhança $\left(\Lambda^{*}\right)$, F, t, Mann-Kendall Sazonal (SMK) e Pettitt para a localidade de Pindorama-SP. Temperatura mínima do ar. Os respectivos valores críticos são 4,61; 1,90; 2,01; [-1,96 a +1,96] e 332,00. 
de Campinas, Cordeirópolis, Monte Alegre do Sul, Pindorama e Ribeirão Preto, data inicial de alteração em 1982. Essa característica, por sua vez, pode ser vista como um indício de que forçantes radioativas de escala global, também estejam presentes nas taxas de elevação dos valores de Tmin no Estado de São Paulo.

Mesmo em uma primeira análise é bastante evidente que os indícios de tendência ou variações climáticas, presentes nas séries de Tmax (Figuras 8 a 13), são consideravelmente inferiores aos observados nas séries de Tmin. Na localidade de Ubatuba, foram observadas tendências significativas de elevação em sete meses. Nas localidades de Piracicaba, Pindorama e Monte Alegre do Sul, o SMK superou o valor crítico em cinco, quatro e dois meses, respectivamente. Nesse último posto meteorológico chega-se a observar magnitudes negativas e significativas desse método não paramétrico $(-2,15$; setembro). Nas localidades de Campinas e Cordeirópolis, essa característica de elevação foi observada em apenas um mês; não sendo verificada nas localidades de Mococa e Ribeirão Preto. Essa última característica parece corroborar, mais uma vez, as análises de Vincent et al. (2005), em relação à queda na
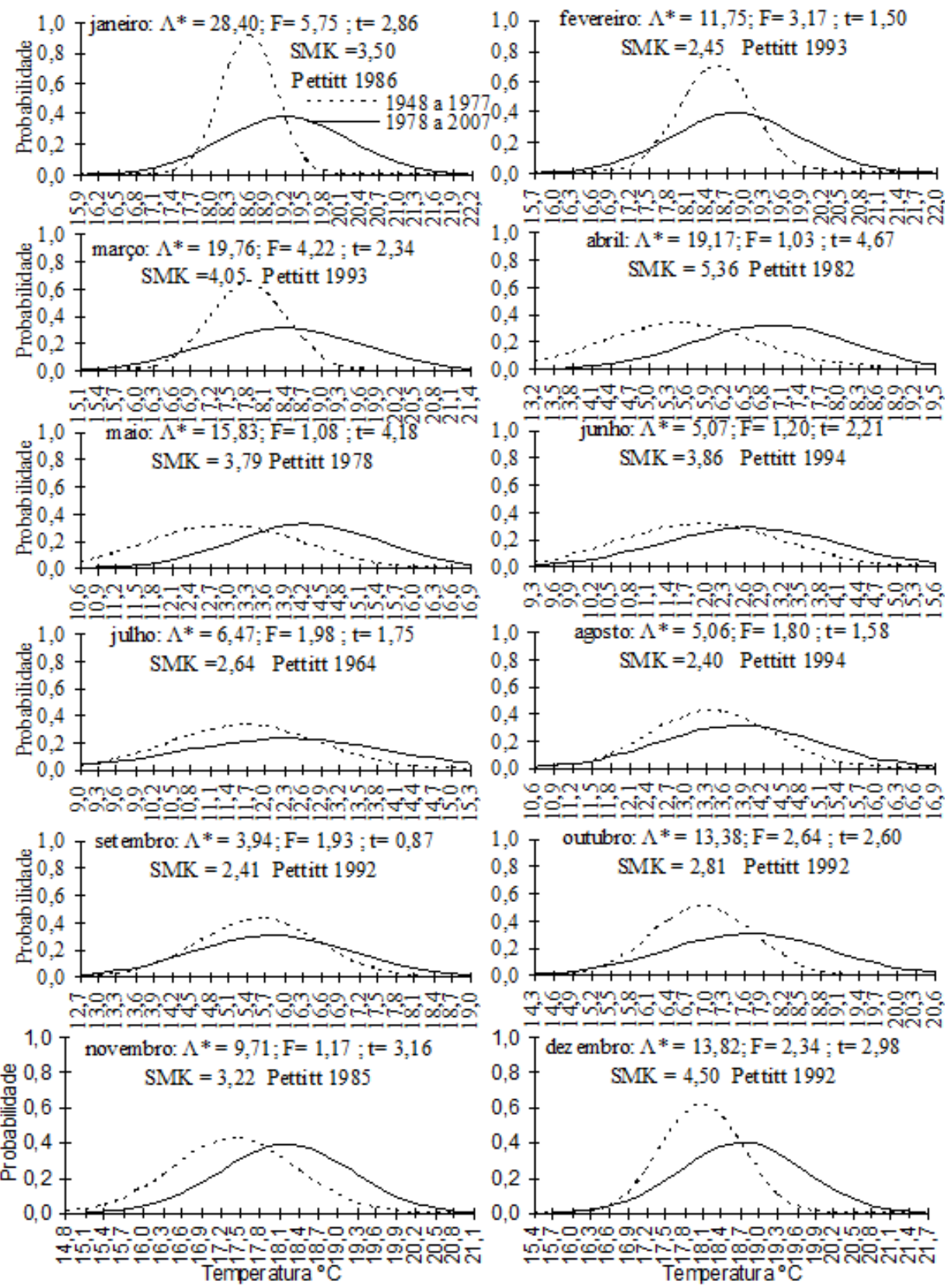

Figura 6 - Aplicação dos testes razão da verossimilhança $\left(\Lambda^{*}\right)$, F, t, Mann-Kendall Sazonal (SMK) e Pettitt para a localidade de Ribeirão Preto-SP. Temperatura mínima do ar. Os respectivos valores críticos são 4,61; 1,86; 2,01; [-1,96 a +1,96] e 367,00. 
significância das tendências de elevação nos valores diários de temperatura máxima na América do Sul (quando comparada as da Tmin). Segundo esses autores, as significativas alterações nos valores de temperatura estão fundamentalmente ligadas ao aumento (queda) do número de dias com noites quentes (noites frias). Essa indicação, embora para a escala diária, vai também ao encontro das diferentes taxas de elevação, aqui detectadas, entre as séries de Tmin e Tmax. Infere-se, portanto, que a(s) forçantes radioativa(s) causadora(s) das alterações nos valores de temperatura do ar parecem agir/restringir, de forma mais significante, na taxa de resfriamento noturno do que nas taxas de elevação da temperatura do ar ao longo do período diurno. Contudo, ressalta-se novamente, que, embora com menor significância do que verificado nas séries de Tmin, na localidade litorânea de Ubatuba, ocorrem os maiores indícios de elevação nos valores de Tmax entre todas as séries analisadas.

Campinas: O SMK indica tendências significativas de elevação apenas nos agrupamentos mensais de Abril. Para
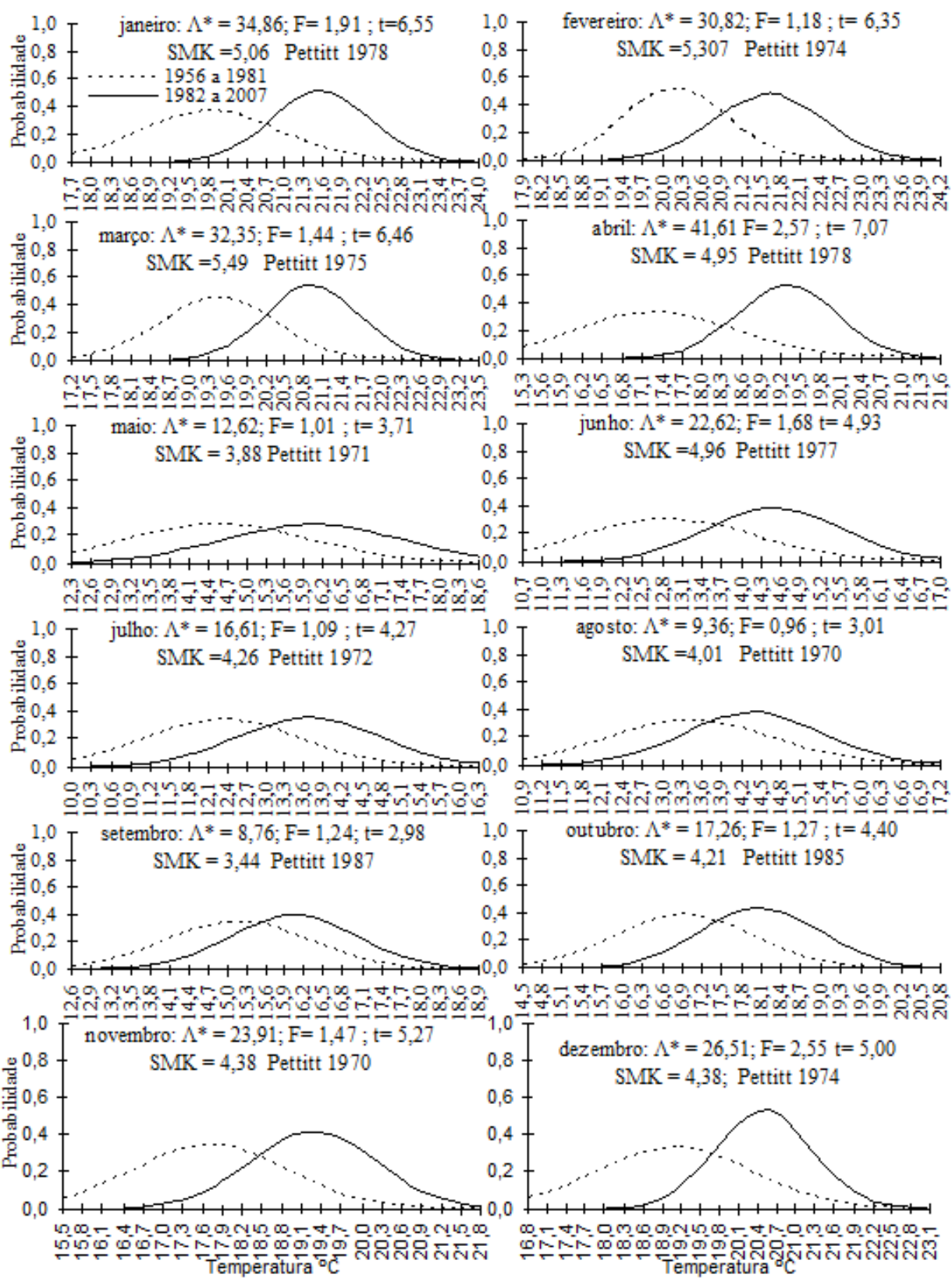

Figura 7 - Aplicação dos testes razão da verossimilhança ( $\left.\Lambda^{*}\right)$, F, t, Mann-Kendall Sazonal (SMK) e Pettitt para a localidade de Ubatuba. Temperatura mínima do ar. Os respectivos valores críticos são 4,61; 1,96; 2,01; [-1,96 a +1,96] e 297,00. 
esse mês, também é observada significativa alteração na forma e na escala das FDPN associadas às duas amostras de 30 anos $\left(\Lambda^{*}\right.$ significativo). Segundo o teste de Pettitt, a data aproximada dessa alteração é 1984. De acordo com o teste F, há homocedasticidade das variâncias em todos os agrupamentos mensais. Ressalta-se que no mês de Setembro há, de acordo com os testes te $\Lambda^{*}$, significativo deslocamento à esquerda da FDPN associada aos anos de 1978 a 2007. Para esse mês o SMK foi de $-1,58$ (queda nos valores de Tmax).
Cordeirópolis: O SMK indica tendências significativas de elevação apenas no mês de Abril. Para esse mês, também é observada significativa alteração na forma e na escala das FDPN associadas às duas amostras de 30 anos, indicada pelo $\Lambda *$ significativo. Para esse agrupamento mensal, é também interessante ressaltar que apesar de serem verificadas tendências monótonas de elevação nos valores de Tmin (SMK significativo) e importantes variações nas formas das FDPN associadas aos dois sub-perídos, não houve, por parte do teste $t$, indicação

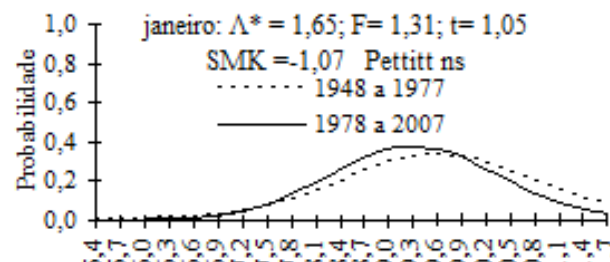

1,0
0,8 $\quad \begin{aligned} \text { fevereiro: } \Lambda^{*} & =1,09 ; \mathrm{F}=1,41 ; \mathrm{t}=0,49 \\ \mathrm{SMK} & =0,59 \text { Pettitt ns }\end{aligned}$

0,6
0,4
0,2

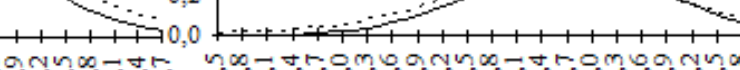

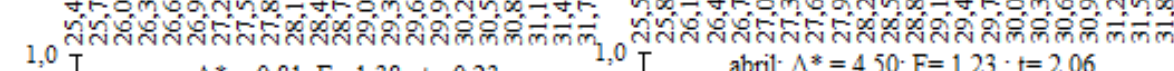

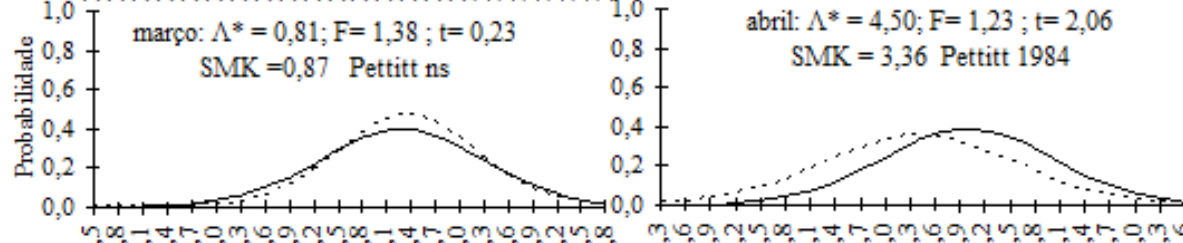

no-

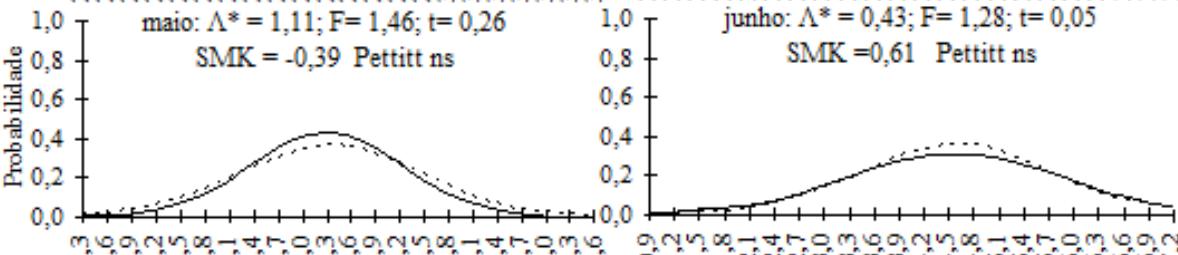

moornm-

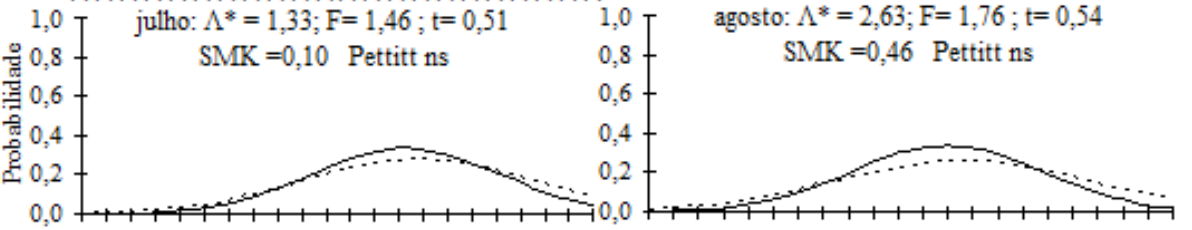

rombonn $\rightarrow$ -

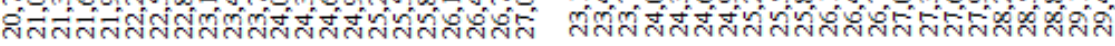

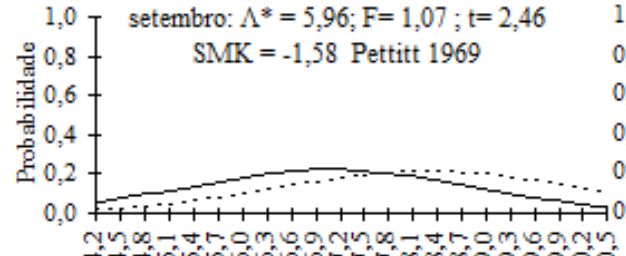

outubro: $\Lambda^{*}=2,24 ; \mathrm{F}=1,30 ; \mathrm{t}=1,31$

$\mathrm{SMK}=1,28$ Pettitt ns

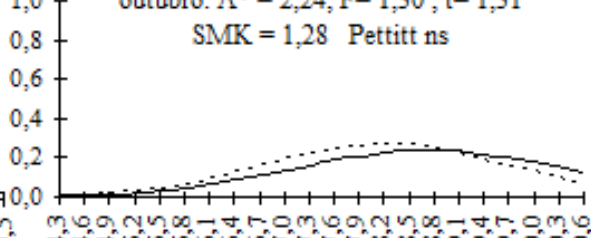

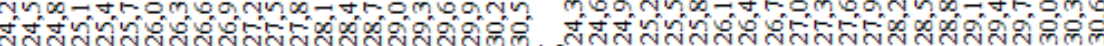

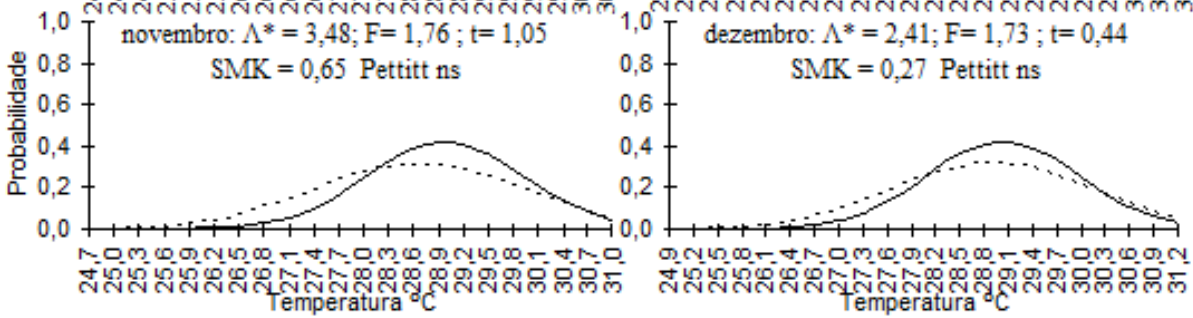

Figura 8 - Aplicação dos testes razão da verossimilhança $\left(\Lambda^{*}\right)$, F, t, Mann-Kendall Sazonal (SMK) e Pettitt para a localidade de Campinas-SP. Temperatura máxima do ar. Os respectivos valores críticos são 4,61; 1,86; 2,01; [-1,96 a +1,96] e 367,00. 
de alterações significativas nas médias aritméticas das amostras sob análise. Ainda que a adaptação do teste t para amostras com variâncias diferentes (queda em seu grau de liberdade) reduza a robustez desse método, essa característica pode ser vista como um exemplo da fragilidade em estudar/caracterizar o clima de uma região apenas com base nessa medida de posição central. Embora, as médias mensais de Abril, considerando os anos de 1948 a 1977 e 1978 a 2007, sejam numericamente próximas (respectivamente, 27,2 e $27,6^{\circ} \mathrm{C}$ - teste $\mathrm{t}$ não significativo), os demais métodos indicam acentuada alteração nos valores de Tmin entre os dois sub-períodos. Segundo o teste de Pettitt, a data aproximada dessa alteração é, mais uma vez, o ano de 1984. De acordo com o teste $\mathrm{F}$, há homocedasticidade da variância nos demais 11 agrupamentos mensais. Ressalta-se que no mês de Setembro há, de acordo com os testes t e $\Lambda^{*}$ (assim como observado na localidade de Campinas), significativo deslocamento à esquerda da FDPN associadas aos anos de 1978 a 2007. Para esse mês o SMK foi de -1,61 (queda nos valores de Tmax).
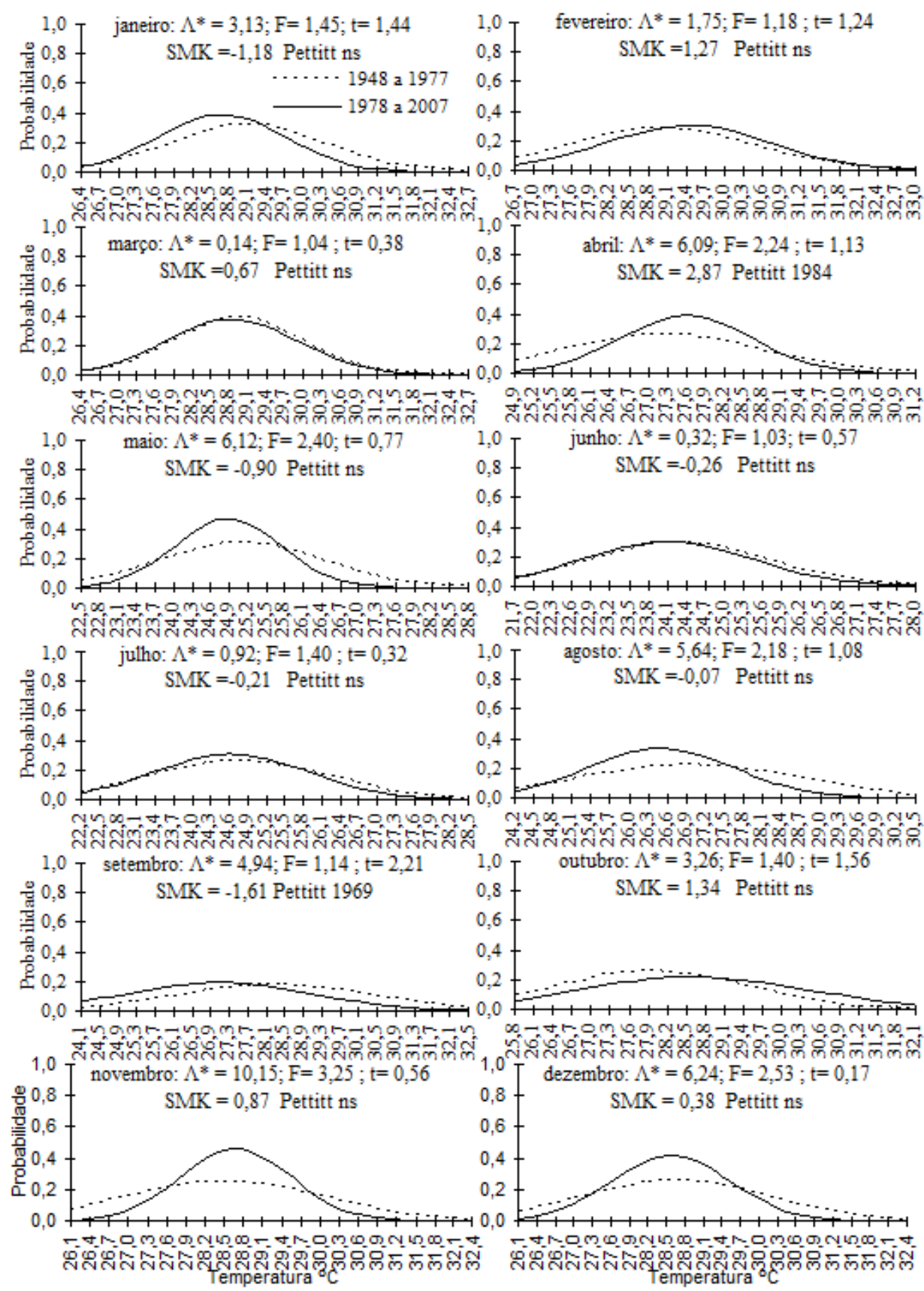

Figura 9 - Aplicação dos testes razão da verossimilhança ( $\left.\Lambda^{*}\right)$, F, t, Mann-Kendall Sazonal (SMK) e Pettitt para a localidade de Cordeirópolis-SP. Temperatura máxima do ar. Os respectivos valores críticos são 4,61; 1,86; 2,01; [-1,96 a +1,96] e 367,00. 
Monte Alegre do Sul: O SMK indica tendências monótonas de elevação nos valores de Tmax nos meses de Fevereiro e Abril. Para esses agrupamentos também são verificados valores significativos dos testes t e $\Lambda^{*}$. Especificamente para o mês de Abril, assim como observado em Campinas e Cordeirópolis, o teste de Pettitt indica que a data aproximada de alteração no regime da variável meteorológica sob estudo é o ano de 1984. As amostras de Agosto são as únicas que não apresentam homocedasticidade das variâncias. Nesse último mês, assim como em Setembro o $\Lambda^{*}$ indica importante deslocamento à esquerda das FDPN relativas aos últimos 30 anos. Para as amostras de Setembro essa queda nos valores de Tmin é mais marcante, tendo em vista o valor negativo e significativo do SMK.

Pindorama: O SMK indica tendências monótonas de elevação nos valores de Tmax nos meses de Outubro e Abril. Para esses agrupamentos, também são verificados valores significativos dos testes t e $\Lambda^{*}$. Especificamente para o mês
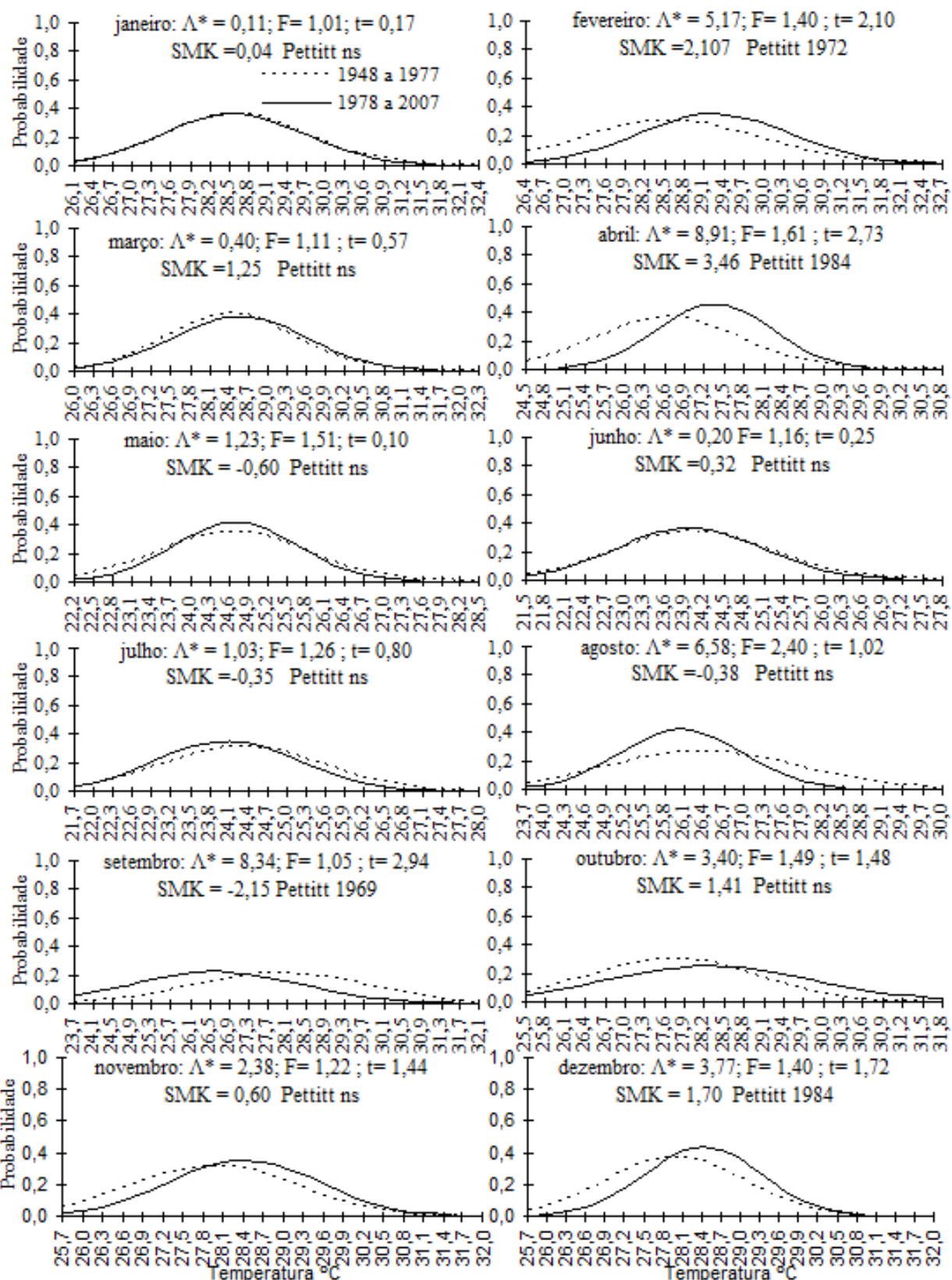

Figura 10 - Aplicação dos testes razão da verossimilhança $\left(\Lambda^{*}\right)$, F, t, Mann-Kendall Sazonal (SMK) e Pettitt para a localidade de Monte Alegre do Sul-SP. Temperatura máxima do ar. Os respectivos valores críticos são 4,61; 1,86; 2,01; [-1,96 a +1,96] e 367,00. 
de Abril, o teste de Pettitt indica que o ponto aproximado dessa alteração é o ano de 1982. Apenas nas amostras de Outubro não foram observadas homocedasticidade das variâncias. Nos meses de Novembro e Dezembro os testes t e $\Lambda^{*}$ indicam importante deslocamento à esquerda das FDPN relativas aos últimos 30 anos, embora essas variações não tenham, de acordo com o SMK, resultado em significativas tendências monótonas nos valores de Tmax. Assim como verificado em todas as demais localidades o SMK de Setembro permaneceu abaixo de zero $(-0,51)$.
Mococa e Ribeirão Preto Essas localidades foram as que apresentaram os maiores números de meses com valor negativo do SMK (10 e 6 meses, respectivamente). Para Mococa, o SMK indicou queda significativa nos dados relativos ao mês de Setembro. Essa característica pode ser observada nos meses de Maio na localidade de Ribeirão Preto. Ao contrário do observado em todas as demais regiões, não houve detecção de significativas tendências monótonas de elevação nos agrupamentos mensais de Abril, embora para esse mês, o teste $\Lambda^{*}$ indique, para
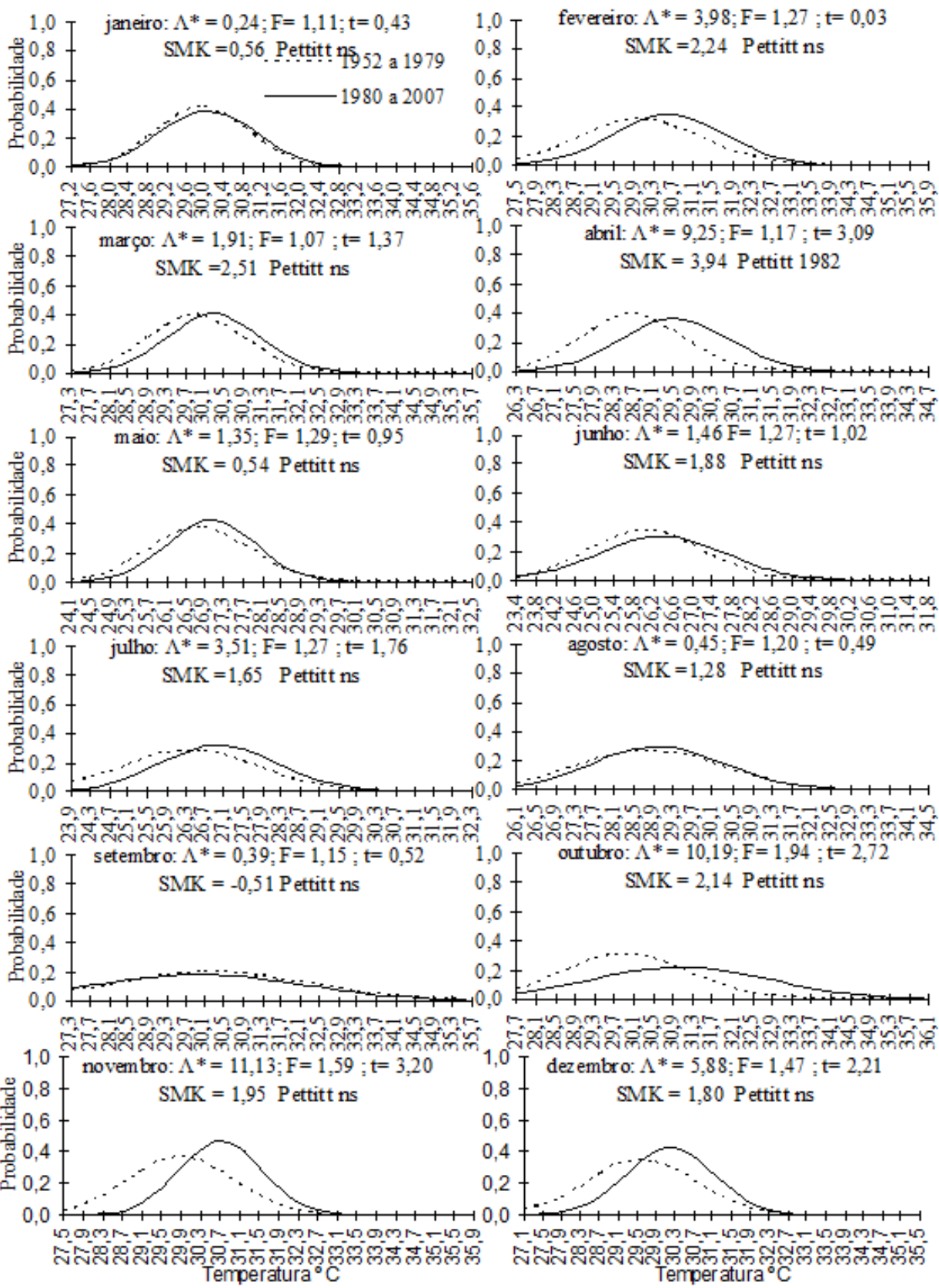

Figura 11 - Aplicação dos testes razão da verossimilhança $\left(\Lambda^{*}\right)$, F, t, Mann-Kendall Sazonal (SMK) e Pettitt para a localidade de Pindorama-SP. Temperatura máxima do ar. Os respectivos valores críticos são 4,61; 1,90; 2,01; [-1,96 a +1,96] e 332,00. 
Ribeirão Preto, importantes alterações nas probabilidades paramétricas de ocorrência dos valores de Tmin, entre os dois sub-períodos de 30 anos. Ainda para essa última localidade não houve homocedasticidade das variâncias nos meses de Abril, Novembro e Dezembro. Analisando-se as FDPN associadas à esses três últimos espaços amostrais, verifica-se, especialmente para o mês de Abril, elevação na probabilidade de ocorrência nos valores próximos a média aritmética ocorrida nas amostras de 1978 a 2007. Nas séries da localidade de Mococa não houve homocedasticidade das variâncias nos meses de Novembro e Dezembro. $\mathrm{O} \Lambda$ * indicou deslocamento significativo à esquerda da FDPN associada ao sub-período mais recente. Ressalta-se, para as duas localidades, as diferenças entre as variabilidades temporais presentes nas séries de Tmax (predominância de valores negativos do SMK) e de Tmin (predominância de valores positivos do SMK). Essa característica bastante distinta entre
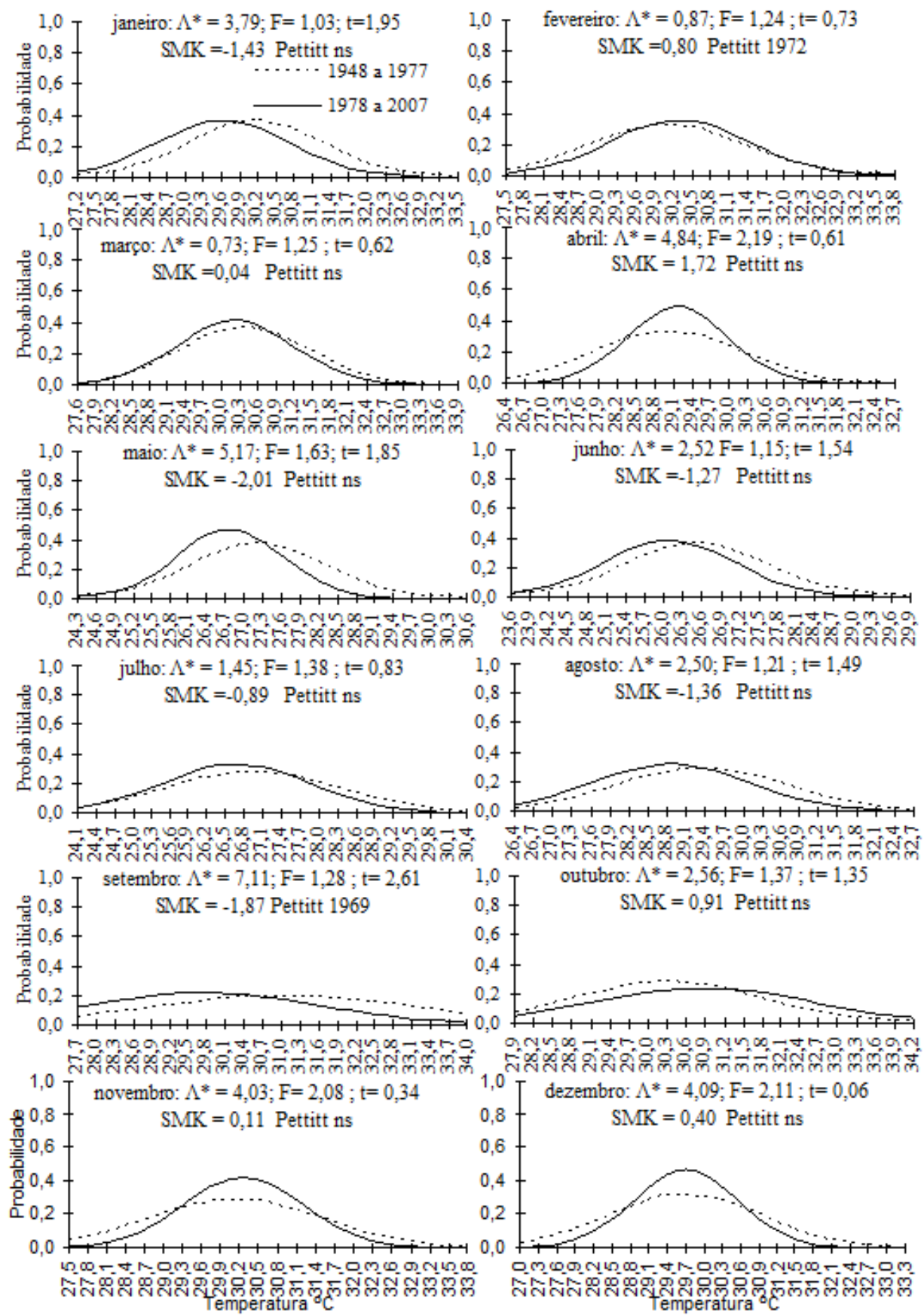

Figura 12 - Aplicação dos testes razão da verossimilhança ( $\left.\Lambda^{*}\right)$, F, t, Mann-Kendall Sazonal (SMK) e Pettitt para a localidade de Ribeirão Preto-SP. Temperatura máxima do ar. Os respectivos valores críticos são 4,61; 1,86; 2,01; [-1,96 a +1,96] e 367,00. 
essas duas variáveis oriundas dos mesmos locais geográficos é mais um indicativo da inferência estatística de que a(s) forçante(s) radiotativa(s) causadoras das tendências e variações climáticas relativas a temperatura do ar, no Estado de São Paulo, parecem interagir, de forma mais marcante, na taxa de resfriamento noturno do que nas taxas de elevação ao longo do período diurno.

Ubatuba: O SMK indica tendências significativas de elevação nos meses de Março a Junho e Outubro a Dezembro. No mês de Abril, observam-se os indícios mais marcantes de tendências (valores elevados do SMK) e variação climáticas ( $\Lambda^{*}$ elevado). Ainda para esse último agrupamento mensal, o teste de Pettitt indica que a data de alteração nos valores de
Tmax ocorre em 1980. Apenas nas amostras de Fevereiro não há homocedasticidade da variância. Entretanto, ressalta-se significativa alteração nos parâmetros das funções densidade de probabilidade associadas aos agrupamentos mensais de Fevereiro, Abril, Maio Outubro, Novembro e Dezembro. No mês de Setembro, observa-se o valor -0,03 do SMK.

De forma análoga às análises voltadas aos dados de Tmin, verificam-se para a Tmax, marcantes indícios de alterações de ordem climática nos agrupamentos mensais de Abril. Novamente a data inicial dessa tendência de elevação ocorreu de forma aproximadamente concomitante entre todas as localidades com início na década de 1980. Essa característica, associada a trabalhos

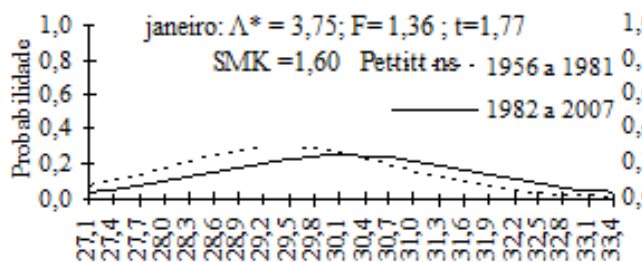

1,0
0,8 $\quad \begin{aligned} \text { fevereiro: } \Lambda^{*} & =5,21 ; \mathrm{F}=1,44 ; \mathrm{t}=2,10 \\ \mathrm{SMK} & =1,77 \text { Pettitt ns }\end{aligned}$
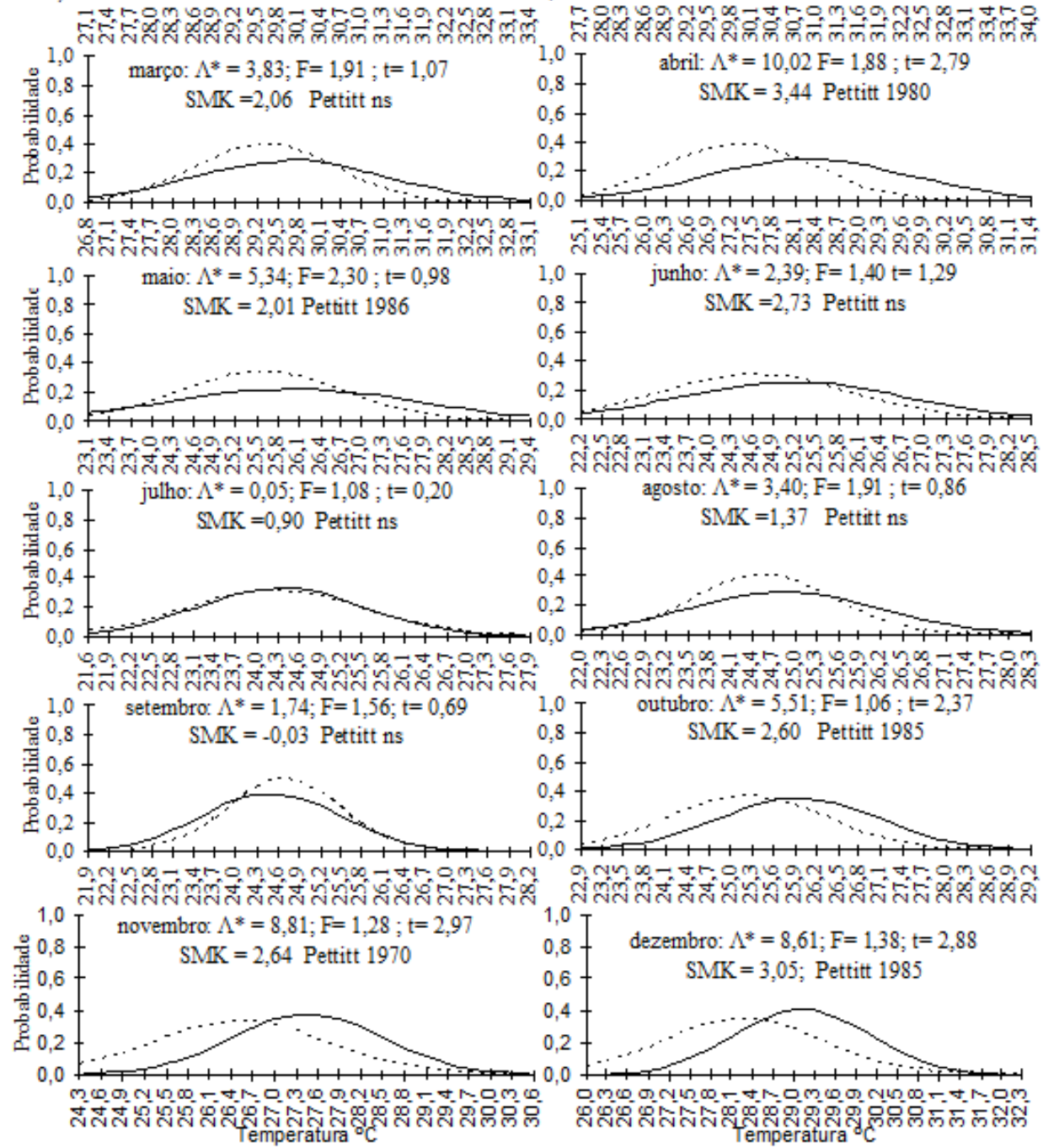

Figura 13 - Aplicação dos testes razão da verossimilhança $\left(\Lambda^{*}\right)$, F, t, Mann-Kendall Sazonal (SMK) e Pettitt para a localidade de Ubatuba. Temperatura máxima do ar. Os respectivos valores críticos são 4,61; 1,96; 2,01; [-1,96 a +1,96] e 297,00. 
como os do IPCC (2007), que indicam elevação da temperatura média global nos últimos 50 anos, pode ser vista como um indício de que forçantes de escala global estejam fortemente relacionadas à essas taxas de elevação, detectadas nas séries de temperatura do ar (máxima e mínima) dos meses de Abril no Estado de São Paulo.

\section{CONCLUSÕES}

As séries de temperatura mínima mensal das localidades de Campinas, Cordeirópolis, Ribeirão Preto e, especialmente, Ubatuba, apresentam fortes indícios de tendências e variações climáticas. Nas séries de Monte Alegre do Sul e Pindorama tais indícios são observados de forma pouco significativa. As significâncias das alterações de ordem climática, observadas nas séries mensais de temperatura máxima, são de forma geral, bastante inferior às observados nas séries mensais de temperatura mínima. Contudo, assim como para as séries de Tmin, nos valores de Tmax da localidade de Ubatuba são verificadas as elevações mais significativas entre todas as séries analisadas.

Sob o ponto de vista temporal, o mês de Abril, foi o agrupamento mensal mais sujeito a elevações nas séries de Tmax e de Tmin. Essas alterações ocorreram com considerável concomitância no início da década de 1980 em todas as localidades investigadas. Em contra partida, verificou-se também que as séries de temperatura do ar (máxima e mínima), relativas ao mês de Setembro, parecem ser as menos afetadas por tendências temporais de elevação.

\section{AGRADECIMENTO}

O autor cordialmente agradece a Dra. Claudia von Brömssen (Swedish University Of Agricultural Science) pelas construtivas e valiosas explicações relacionadas à detecção de tendências em séries temporais compostas por dados autocorrelacionados.

\section{REFERÊNCIAS BIBLIOGRÁFICAS}

ALEXANDER, L.V.; ZHANG, X.; PETERSON, T.C.; CAESAR, J.; GLEASON, B.; TANK, A.M.G; HAYLOCK, M.; COLLINS, D.; TREVIN, B.; RAHIMZADEH, F.; TAGIPOU, A.; RUPA KUMAR, K.; REVADEKAR, J.; GRIFFITHS, G.; VINCENT, L.; STEPHENSON, D.; BURN, J.; AGUILLAR, E.; TAYLOR, M.; NEW, M.; ZHAI, P.; RUSTICUCCI, M.; VASQUEZ-AGUIRRE, J.L. Global observed changes in daily climate extremes of temperature and precipitation. Journal of Geophysical Research, Washington, v. 111, 2006. Disponível em: <http://www.agu.org/journals/jd/ jd0605/2005JD006290/>. Acesso em: 02 fev. 2009.
BACK, A.J. Aplicação de análise estatística para identificação de tendências climáticas. Pesquisa Agropecuária Brasileira, Brasília, v.36, p.717-726, 2001

BAYAZIT, M.; ONOZ, B. To prewhiten or not prewhiten in trend analysis? Hydrological Science Journal, Wallingford, v.52, n.4, p.611-624, 2007.

CRUTCHER, H.L. A note on the possible misuse of the Kolmogorav-Smirnov test, Journal of Applied Meteorology, v.14, p.1600-1603, 1975

DALE, R.F. Applied Climatogy. Indiana: Purdue University, 1968. 125p.

FREI, C.; SCHAR, C. Detection probability of trends in rare events: Theory and application to heavy precipitation in the Alpine region. Journal of Climate, Zurich, v.14, p.15681584, 2000.

HAMED, K.H.; RAO, A.R. A modified Mann-Kendall trend test for auto-correlated data. Journal of Hydrology, Amsterdam, v.204, p.182-196, 1998.

HIRSCH, R.M.; SLACK , J.R. A nonparametric trend test for seasonal data with serial dependence. Water Resources Research, Washington, v.20, p.727-732, 1984.

HIRSCH, R.M.; SLACK J.R.; SMITH, R.A. Techniques of trend analysis for monthly water quality data. Water Resources Research, Washington, v.18, p.107-121, 1982.

IPCC, Climate Change 2007: The Physical Science Basis, Contribution of Working Group I to the Fourth Assessment Report of the Intergovernmental Panel on Climate Change, HOUGHTON, JT, (Ed,), Cambridge University Press, 2007.

KARL, T.R.; NICHOLLS, N.; GHAZI, A. 1999. CLIVAR:GCOS:WMO workshop on indices and indicators for climate extremes. Climatic Change Washington, v. 42, p.3-7, 1999.

KENDALL, M.A.; STUART, A. The advanced theory of statistics. Londres: Charles Griffin \& Company Limited, 1967. 690p.

LETTENMAIER, D.P.; WOOD, E.F.; WALLIS, J.R. Hydroclimatological trends in the continental United States, 1948-88. Journal of Climate, Zurich, v.7, p.586-607, 1994.

MANN, H.B. Non-parametric tests against trend. Econometrica, Bristol, v.13, p.245-259, 1945.

MARENGO, J.; NOBRE, C.; RAIGOZA, D.; VALVERDE, M.; PISNITCHENKO, I.A.; OLIVEIRA, J.C.M. Boletim do Projeto: uso de cenários de mudanças climáticas regionais em estudos de vulnerabilidade e adaptação no Brasil e na América do Sul (GOF-UK-CPTEC), 2007. Disponível em: <www.cptec.inpe.br/mudancas_climaticas $>$. Acesso em: 1 dez. 2008.

MORTATTI, J.; BORTOLETTO, M. J.; MILDE, L.C.E.; PROSBST, J. Hidrologias dos rios Tietê e Piracicaba: Séries temporais de vazão e hidrogramas de cheia. Revista 
de Ciência \& Tecnologia, Piracicaba, v.12, n.23, p.55-67, 2004.

ORGANIZAÇÃO METEOROLÓGICA MUNDIAL: Climatic Change. WMO, Geneva, Switzerland, 80p. 1966.

PETTITT, A.N. A non-parametric approach to the change-point problem. Journal of Applied Statistics, Park, v.28, n.2, p.126-135, 1979.

PINTO, H.S.; ASSAD, E.D.; ZULLO JR., J.; EVANGELISTA, S.R.M.; MACEDO JR., C.; PELLEGRINO, G.Q.; OTAVIAN, A.F.; COLTRI, P.P.; ÁVILA, A.M.H.; CORAL, G.; EVANGELISTA, B. A. Aquecimento global e a nova geografia da produção agrícola no Brasil. EMBRAPA/ Unicamp. Campinas, ago., 2008. 81p.

SANSIGOLO, C.S.; NERY, J.T. Distribuição de extremos de temperatura mínima no estado do Paraná. Revista Brasileira de Agrometeorologia, Santa Maria, v.8, n.2, p.247-253, 2000.

SCHICKEDANZ, P.T.; KRAUSE, G.F. A test for the scale parameters of two gamma distributions using the generalized likelihood ratio. Journal of Applied Meteorology, Boston, v.9, p.13-16, 1969.

VICTORIA, R.L.; MARTINELLI, L.A.; MORAES, J.M.; BALLESTER, M.V.; KRUSCHE, A.V.; PELLEGRINO, G.; ALMEIDA, R.M.B.; RICHEY, J.E. Surface air temperature variations in the Amazon Region and its borders during this century. Journal of Climate, Zurich, v.11, n.5, p.1105-1110, 1998.
VINCENT, L.A.; PETERSON, T.C.; BARROS, V.R.; MARINO, M.B.; RUSTICUCCI, M.; CARRASCO, G.; RAMIREZ, E.; ALVES, L.M.; AMBRIZZI, T.; BERLATO, M.A.; GRIMM, A.M.; MARENGO, J.A.; MOLION. L.; MONCUNILL, D.F.; REBELLO, E.; ANUNCIAÇÃO, Y.M.T.; QUINTANA, J.; SANTOS, J.L.; BAEZ, J.; CORONEL, G.; GARCIA, J.; TREBEJO, I.; BIDEGAIN, M.; HAYLOCK, M.R.; KAROLY, D. Observed trends in indices of daily temperature extremes in South America 1960-2000. Journal of Climate, Zurich, v.18, p.5011-5023, 2005.

VON STORCH, H.; ZWIERS, F.W. Statistical Analysis in Climate Research. Cambridge: Cambridge University Press, 1999. 494p.

WILKS, D.S. Theoretical probability distributions. In: Statistical methods in the atmospheric sciences. San Diego: Academic Press, 2006. p.102-104.

ZULlO JR., J.; PINTO, H.S.; ASSAD, E.D. Impact assessment study of climate change on agricultural zoning, Meteorological Applications, v.13, p. 69-80 Cambridge University Press, 2006 doi:10.1017/S135048270600257X 